Journal of Accident and Emergency Medicine 1995 12, 282-285

\title{
Hepatitis B vaccination: uptake by medical staff in accident and emergency departments
}

\author{
P. A. NEE', P. E. RANDALL², \& J. HEYWORTH ${ }^{3}$
}

${ }^{1}$ Whiston Hospital, Prescot, Merseyside, ${ }^{2}$ North Manchester General Hospital and ${ }^{3}$ Queen Alexandra Hospital, Portsmouth, UK

\section{SUMMARY}

To assess the current uptake of hepatitis B vaccine and attitudes towards immunization among accident and emergency practitioners in the UK, a postal survey was carried out. Questionnaires were sent to $\mathbf{7 4 2}$ members of the British Association for Accident and Emergency Medicine (BAEM). Four hundred and six $(55 \%)$ replies were received. Of 351 respondents in career-grade posts $309(88 \%)$ had received a full course of immunizations. Five respondents were not immunized and not intending to be so, reporting 13 different factors influencing their decisions. The risks of hepatitis $B$ in nonimmune subjects are discussed, as are new government guidelines on the protection of health care workers from hepatitis B infection.

Key words: hepatitis B, immunization, infection

\section{INTRODUCTION}

In 1988 the uptake of hepatitis B immunization among trainees and consultants in accident and emergency (A\&E) medicine was poor. Only $22 \%$ of senior registrars and $\mathbf{2 6} \%$ of consultants surveyed had been immunized. ${ }^{1}$ The main reasons for these low rates were unjustified fears about the safety of the plasma-derived vaccine then available and failure to accept that A\&E staff were at risk. Concern was also expressed over rates of seroconversion and the degree of protection afforded by the vaccine.

In the six years since then there have been two major changes. Firstly, the development of a new, genetically engineered vaccine and, secondly, the publication of government guidelines which indicated that hospitals must have offerred immunization to all surgeons by the middle of 1994 . Other health care workers engaging in 'exposure-prone procedures' should have been immunized by the following year. ${ }^{2}$
The present study was undertaken in 1993 to assess the current status among A\&E practitioners with regard to uptake of the new vaccine and attitudes towards immunization in the light of these developments.

\section{SUBJECTS AND METHODS}

Early in 1993 a confidential questionnaire was sent to every member of the BAEM. Members were asked to indicate their present grade and hepatitis $B$ immunization status. Those respondents who did not intend to become immunized against hepatitis $B$ were asked to state the reasons behind this decision.

The immunization status of each respondent was classified into one of eight categories (Table 1).

\section{RESULTS}

Seven hundred and forty two questionnaires were sent out and 406 were returned (55\%). The results are summarized in Table 2.

The BAEM mailing list includes some members not currently employed in UK A\&E departments, such as those who are working abroad and retired members. Membership of the BAEM is also held by practitioners in other specialties and a small number of senior house officers with an interest in emergency medicine. The $\mathbf{3 5 1}$ respondents in senior career posts (consultant, associate specialist, registrar/senior registrar and staff grade) represent $65 \%$ of the 538 doctors whose chosen career is A\&E medicine and who currently work in A\&E departments in this country.

Of 351 career-grade A\&E staff, 309 (88\%) had received a full course of immunizations. Two hundred and forty-five $(\mathbf{7 9} \%)$ of these reported a satisfactory antibody response. Six UK-based A\&E 
Hepatitis

immunization

\begin{tabular}{ll} 
Category & Definition \\
I & Fully immunized, antibody levels checked \\
II & Fully immunized, antibody levels not checked \\
III & Currently undergoing a course of immunization \\
IV & Immune by previous contact \\
V & Not immunized, intending to become immunized \\
VI & Not immunized, not intending to become immunized \\
VII & Not immunized, undecided on whether to become immunized \\
VIII & Previous full course of vaccine with documented inadequate \\
& antibody response \\
\hline
\end{tabular}

Table 1. Categories of hepatitis B immune status

Table 2. Hepatitis B immunization status of career-grade accident and emergency practitioners

\begin{tabular}{|c|c|c|c|c|}
\hline & Consultant & $\begin{array}{l}\text { Associate } \\
\text { specialist }\end{array}$ & $\begin{array}{c}\text { Registrar/ } \\
\text { senior registrar }\end{array}$ & Staff grade \\
\hline No. in post ${ }^{(15)}$ & 248 & $61^{*}$ & $134^{+}$ & $95^{\star}$ \\
\hline No. (\%) respondents & $204(82)$ & $11(18)$ & $114(85)$ & $22(23)$ \\
\hline \multicolumn{5}{|l|}{ Category } \\
\hline $\mathbf{I}$ & 135 & 7 & 86 & 17 \\
\hline II & 36 & 4 & 21 & 3 \\
\hline III & 8 & - & 3 & 1 \\
\hline IV & 6 & - & 1 & - \\
\hline $\mathbf{v}$ & 6 & - & - & 1 \\
\hline VI & 3 & - & - & - \\
\hline VII & 2 & - & - & - \\
\hline VIII & 8 & - & 3 & - \\
\hline
\end{tabular}

* Personal communication, Mr Sean Gregory, NHSE, Leeds, UK.

+ Includes one research fellow.

consultants and one trainee were immune by previous contact. Of those immunized and tested, $11(4.3 \%)$ did not produce satisfactory antibody levels after between three and seven injections each of the vaccine.

Only five respondents were not immunized and not intending to receive the vaccine, despite being currently in practice in UK A\&E departments. These subjects reported a total of 13 factors influencing their decisions. Two expressed doubts about the extent and duration of protection produced by the vaccine; one felt that rates of seroconversion were poor. Three practitioners felt, that it was sufficient to take 'universal precautions' during invasive procedures, but did not specify further; for example, whether goggles were worn. One respondent had not received advice on the benefits of immunization and another had been actively discouraged by a colleague.

Two consultants felt that seroprevalence rates in the UK were so low as to make immunization unnecessary and another objected to mass consultants gave grounds of personal freedom as their main reason for not participating in an immunization scheme, one felt unwilling to have his hepatitis B status tested, whereas another regarded mandatory immunization as an invasion of his 'personal space'.

None of the 406 respondents declared any reservations about the safety of the vaccines available, either in terms of adverse reactions or perceived infective risk.

\section{DISCUSSION}

The present survey represents a comprehensive review of the hepatitis $B$ immunization status of consultants, senior registrars and registrars in A\&E medicine. More than $80 \%$ of practitioners in these grades responded to the questionnaire. The response rates among staff grade doctors and associate specialists were poor by comparison: 23 and $18 \%$, respectively.

Most A\&E practitioners were immunized or intending to become immunized. Only five of 351 
P.A. Nee et al. respondents (1.4\%) were not immunized and not intending to become immunized. The factors influencing the decisions of these five practitioners are discussed in the following. Vaccine safety was not a factor in any of these cases.

\section{Exposure risk}

Infection with the hepatitis B virus represents a significant risk for A\&E practitioners in the UK who are not immunized. The prevalence of carriers in the UK has been estimated at $0.1-0.5 \%$ of the population. ${ }^{3}$ The exposure risk is greatest in inner-city departments treating large numbers of immigrants from endemic areas (it is estimated that there are $\mathbf{2 0 0}$ million carriers world-wide) as well as intravenous drug abusers and other high risk groups. Hospital attenders in general have a higher rate of hepatitis $B$ carriage than the population at large. The average A\&E department receiving 50000 new patients each year can expect at least one or two carriers each week to pass through the department.

The hepatitis B virus is highly infectious, with a greater than $20 \%$ infection rate when subjects who are not immunized are exposed to blood positive for e antigens. ${ }^{4}$ This contrasts with a rate of $0.5 \%$ for human immunodeficiency virus, which is much less infectious and less robust, as well as having lower seroprevalence in the community. The hepatitis $B$ virus can remain viable in dried blood for at least a week at ambient temperatures. ${ }^{5}$

The incidence of reported cases of acute hepatitis B (466 cases in England and Wales in 1993) is an underestimate as sub-clinical infection is common. ${ }^{6}$ Although complete resolution occurs in $90 \%$ of acute cases, a minority of infected adults go on to develop chronic carrier status, defined as persistence of HBsag in serum for more than 6 months. As well as the obvious consequences for the careers of affected individuals, chronic carriage is a major risk factor for chronic hepatitis, cirrhosis and hepatocellular carcinoma.

\section{Universal precautions}

Accidental injury often occurs during procedures such as minor operations, venepuncture and cannulations. In one busy A\&E department, 212 splash incidents occurred in a single month, mostly in the resuscitation room. ${ }^{7}$ Universal precautions do not confer adequate protection against hepatitis $B$ as it is only a small minority who are able to cases of reported acute hepatitis B occurs in health care workers. In the present survey the prevalence of respondents immune by previous contact (2\%) was similar to the $1.7 \%$ reported in another group of health care workers performing exposure-prone procedures. $^{10}$

\section{Vaccine safety}

In 1988 the plasma-derived vaccine then available was (incorrectly) perceived as being unsafe. Since that time has been superceded by a genetically engineered vaccine. The ' $S$ ' gene, which codes for surface antigen, was first isolated in 1987. During manufacture of the vaccine the gene is inserted into a yeast host. The yeast cells multiply in a fermentation process and excess immunogenic surface antigen is produced, then separated and purified before being processed into vaccine. The previous plasma-derived vaccine was rendered safe only after an expensive purification process, whereas the new vaccine is widely accepted as being free of any infective hazard.

Adverse effects are protean, but generally minor, such as redness and soreness at the injection site, headache, abdominal upset, fever and rashes. Such hypersensitivity reactions are usually caused by the aluminium hydroxide adjuvant or the preservative rather than the surface antigen or yeast protein residue. Arthralgia, occasionally severe when associated with immune complex formation in subjects positive for HLA B27, may rarely occur.

\section{Efficacy of vaccine}

The new vaccine is extremely effective, the usual adult dosage schedule (for subjects less than $\mathbf{5 0}$ years old) of $20 \mu \mathrm{g}$ intramuscularly repeated at 1 and 6 months produces protective antibody titres of greater than $100 \mathrm{mlu} \mathrm{mL}^{-1}$ in $86 \%$ of healthy subjects. Those who do not respond with this schedule may produce adequate antibody levels after one or two additional doses. ${ }^{11}$ The incidence of inadequate antibody response in the present survey (minimum $3.4 \%$, maximum $4.3 \%$ ) is similar to the previously reported range of $1-4 \% .^{12}$

\section{Cost of pre-vaccination testing versus mass immunization}

The genetically engineered vaccine (ENGERIX B; SmithKline Beecham Pharmaceuticals) costs £34 per course, as opposed to $£ 63.50$ for the plasma-derived 
Hepatitis

immunization product. The main reason for the price difference is the lack of necessity for additional purification stages of the newer vaccine.

There is no need for pre-vaccination testing. The cost of mass immunization of health care workers should be set against the potential industrial injury compensation and legal costs if a health care worker should infect a patient. Between 1975 and 1990 in England, Wales and Northern Ireland, at least 95 patients were infected with hepatitis B virus by surgical staff. ${ }^{13}$

\section{Advice on vaccination}

New government guidelines indicate that practitioners engaged in exposure-prone procedures (defined as procedures associated with the risk of contact with blood or blood-stained body fluids) must be offered hepatitis $B$ vaccination. ${ }^{2}$ Practitioners must produce proof of immunity or non-response to a full course of immunization. Non-responders will be tested for e antigen and, if positive, will be prohibited from undertaking exposure-prone procedures and offered alternative work. Those who refuse to undergo testing will be treated as if they were positive for e antigen and will be offered re-deployment or re-training. Trusts may be able to take disciplinary action against practitioners who are unwilling to accept these arrangements. ${ }^{14}$

The British Medical Association and the Royal College of Surgeons advise practitioners to comply with these recommendations, even though they are not to be policed by the NHS Executive. Trusts are expected to implement the guidelines themselves.

\section{CONCLUSIONS}

This study indicates that there has been a significant change in the attitude of A\&E practitioners towards immunization against hepatitis $B$ since 1988. Most career-grade A\&E practitioners are now fully immunized and most of the remainder are intending to become immunized. Implementation of the new government guidelines on hepatitis B immunization should therefore present few difficulties for medical staff in the specialty of A\&E medicine.

\section{ACKNOWLEDGEMENTS}

The authors thank Olive Tracey and Emma Butler for typing the manuscript. Emma Spiller of SmithKline Beecham Pharmaceuticals assisted with the provision of background data on the development of the genetically engineered vaccine.

\section{REFERENCES}

1. Heyworth J. (1988) Hepatitis B vacccination in United Kingdom accident and emergency departments. Archives of Emergency Medicine 5, 59-68.

2. NHSME (1993) Protecting health care workers and patients from hepatitis B. (HSG (93) 40). NHSME, Leeds.

3. Association of Anaesthetists (1988). AIDS and Hepatitis B. Guidelines for Anaesthetists. Association of Anaesthetists, London

4. Department of Health (1990) Guidance for clinical health care workers: Protection against infection with HIV and hepatitis viruses. Recommendations of the expert advisory group on AIDS. HMSO, London.

5. Bond W.W., Favero M.S., Petersen N.J. et al. (1981) Survival of hepatitis $B$ after drying and storage for one week. Lancet 1, 550-551.

6. Public Health Laboratory Service (1993) Communicable Disease Report Vol. 3 (51), p. 232. PHLS, London.

7. Littlechild P., Macmillan A. White M.M. \& Steedman D.J. (1992) Contamination of skin and clothing of accident and emergency personnel. British Medical Journal 305, 156 -157.

8. Public Health Laboratory Service (1975). Acute viral hepatitis B. British Medical Journal 3, 603.

9. Callender M.E., White Y.S. \& Williams R. (1982) Hepatitis B infection in medical and health care personnel. British Medical Journal 284, 324-326.

10. Poole C.J.M. Miller S. \& Fillingham G. (1994) Immunity to hepatitis B among health care workers performing exposure prone procedures. British Medical Journal 309, 94-95.

11. Hepatitis B Expert Panel (1988) Immunization against hepatitis B. Lancet 1, 875-876.

12. Boxall E.H. (1993) Risks to surgeons and patients from HIV and hepatitis. British Medical Journal 306, 652-653.

13. Heptonstall J. (1991) Outbreaks of hepatitis B virus infection associated with infected surgical staff. Communicable Disease Report 1, R81-R85.

14. Delamothe T. (1994) Hepatitis $B$ and exposure prone procedures. British Medical Journal 309, 73-74.

15. Allen P. (1993) Medical and dental staffing prospects in the NHS in England and Wales 1992. Health Trends 25(4), 118-126. 